\title{
NA TRILHA OU O INFERNO DE DAVID GROSSMAN
}

\author{
Saul Kirschbaum*
}

\section{Resumo}

Através do relacionamento de Orah com os israelenses Avram, Ilan, Adam e Ofer - amigo íntimo, marido e filhos -, e também com o palestino Sammy, motorista de táxi e amigo, David Grossman analisa, em $A$ mulher foge, as diversas faces do intrincado relacionamento entre israelenses e palestinos. $\grave{A}$ primeira vista, a trama concerne à preocupação de Orah com a segurança de seu filho Ofer, engajado em uma ação de represália a terroristas palestinos, da qual poderá ser vítima. Porém, no desenvolvimento do romance, deliberadamente lento, à medida que a narrativa mergulha na mente de Orah, com ampla utilização de técnicas de "fluxo de consciência", evidenciam-se outras questões, como a falta de consideração de israelenses para com os sentimentos dos palestinos, por mais que sejam seus "amigos", e a opressão a que soldados israelenses submetem palestinos suspeitos de vínculos com terroristas. Em meio a um conflito sem perspectivas de solução no horizonte, que compromete a própria normalidade da vida no Estado de Israel, o romance é um veemente libelo contra as guerras em geral, pela paz entre israelenses e palestinos, pela valorização da vida independentemente de etnia.

Palavras-chave: ficção política, romance israelense, conflito palestino-israelense, normalização

\footnotetext{
* Pesquisador independente. Doutor em Letras pela Faculdade de Filosofia, Letras e Ciências Humanas da Universidade de São Paulo. <saul.kirschbaum@gmail.com>
} 


\section{Abstract}

Through the relationship between Orah and the Israelis Avram, Ilan, Adam, and Ofer - a close friend, her husband and her sons -, and also the Palestinian Sammy, taxi driver and friend, David Grossman looks, in The Woman Flees the News (To the End of the Land), to the many facets of the intricate relationship between Israelis and Palestinians. At first glance, the plot concerns Orah's anguish about the safety of his son Ofer, engaged in a military act of reprisal against Palestinian terrorists, of which he may become a victim. However, the development of the novel, deliberately slow, as the story delves into the mind of Orah, with extensive use of techniques of "stream of consciousness", will reveal other issues such as the Israeli's lack of consideration for the feelings of Palestinians, even if they are "friends", and the oppression that Israeli soldiers exercise over Palestinians suspected of terrorist ties. In the midst of a conflict without prospects for a solution at the horizon, which undermines the very normalcy of life in the State of Israel, the novel is a passionate libel against wars in general, for the peace between Israelis and Palestinians, and for the value of life, without regard for ethnicity.

Keywords: political fiction, Israeli novel, Palestinian-Israeli conflict, normalization 
L'obiettivo dell'opera e della Cantica potrebbe essere molteplice, ossia riguardare la realtà immediata e quella futura; ma, tralasciando ogni sottigliezza, per parlare brevemente, l'obiettivo della Commedia e di questa cantica consiste nell'allontanare i viventi, durante la loro esistenza, dallo stato de miseria spirituale, per condurli alla salvezza. (Dante Alighieri, “Lettera a Cangrande”, parágrafo 15)

Se o livro que estamos lendo não nos acorda com uma pancada na cabeça, por que o estamos lendo? [...] Um livro tem que ser como um machado para quebrar o mar de gelo que há dentro de nós. (Franz Kafka, carta a Oskar Pollak, 27/1/1904)

0 último romance do escritor israelense David Grossman, Ishá Borarrat Mibessorá, de 2008, lançado no Brasil pela Companhia das Letras, em 2009, com o título A mulher foge, parte de uma situação recorrente e de forte apelo emocional, o temor das mães (e das famílias) israelenses de perder seus filhos, pouco mais do que adolescentes, nas contínuas escaramuças e ações de repressão ao terrorismo palestino, em um estado de guerra não declarada, sem perspectiva de solução no horizonte.

O texto abre com um Prólogo, único capítulo a receber um título, o que o diferencia do conjunto do romance. É narrado no tempo presente, mas ambientado no passado mais remoto da trama, estruturado, basicamente, em discurso direto; a presença do narrador é mínima, caracterizando uma cena de forte marcação teatral. O Prólogo relata como Orah, Avram e Ilan se conheceram quando, jovens de 16 anos, febris, acometidos de doenças contagiosas, permaneceram internados em um hospital do qual todos os outros pacientes haviam sido evacuados. A precariedade mental e física dos jovens confere à cena um caráter fantasmagórico. A época: 1967, a Guerra dos Seis Dias, que opôs Israel a uma frente de países árabes - Egito, Jordânia e Síria -, apoiados por Iraque, Kuwait, Arábia Saudita, Argélia e Sudão. A conversação se trava entre os protagonistas, Orah e Avram, pois Ilan está quase sempre inconsciente. Desenvolve-se um estreito relacionamento entre os jovens, e Orah não é capaz de escolher entre Ilan e Avram. Na sequência, Orah, Ilan e Avram manterão um atormentado triângulo amoroso. 
Alguns anos mais tarde, por ocasião da Guerra do Iom Kipur, Avram cai prisioneiro do exército egípcio, sendo submetido por um mês e meio a torturas - a isso se somando o interrogatório a que é submetido pelo serviço de segurança após seu retorno, por causa da suspeita do próprio exército israelense de que ele tenha fornecido informações vitais ao inimigo -, e perde o interesse pela vida. Orah vai casar com Ilan. Esta situação é geradora de conflitos quase insolúveis, uma vez que poderia ser ao contrário: Ilan e Avram serviam na mesma unidade do exército. Lá pelas tantas, um dos dois pode obter uma licença para o fim de semana; por telefone, pedem a Orah que tire a sorte para ver quem terá a licença e quem (no momento não se sabe) acabará enfrentando o primeiro golpe das forças invasoras. Orah não imagina o que está em jogo no sorteio, e tira o papel com o nome de Ilan. Se tivesse tirado o outro papel, poderia vir a casar com Avram, e Ilan poderia ter sido torturado pelos egípcios. Orah e Ilan são acometidos de um sentimento de culpa em relação a Avram, quase comparável ao experimentado por alguns sobreviventes da Shoá em relação a parentes e amigos que não tiveram a mesma sorte.

Terminado o Prólogo, a narrativa experimenta um salto temporal de mais de 30 anos. Agora, no presente, Orah tem dois filhos: Adam, de 24 anos, é filho de Ilan, mas Ofer, de 21 anos, é filho de Avram. Desde um ano antes da Guerra do Iom Kipur, Orah mantinha relacionamento íntimo ao mesmo tempo com Ilan (que, afinal, viria a ser seu marido) e com Avram (p. 394), mas não se pode ter certeza se Ilan sabia do grau de intimidade do relacionamento de Orah com Avram. Algum tempo depois de Avram ser devolvido pelos egípcios e inquirido pelo exército israelense, Orah, numa tentativa de trazê-lo de volta para uma vida "normal" - Avram estava apático, não se interessava por nenhum trabalho, estava impotente -, o seduziu e ficou grávida. Ilan soube que Orah estava grávida de Avram (Ilan e Orah estavam separados desde o nascimento de Adam), e também Avram soube que Orah ia ter um filho seu. Mas se recusou a lidar com a situação, que poderia obrigá-lo a restabelecer vínculos com a vida. Tentou convencer Orah a abortar, mas, como esta se recusasse, afastou-se de Orah e de Ilan.

O ano do presente da narrativa é um pouco vago: se Adam nasceu em 1974 e está com 24 anos, então a ação se passa em 1996. Neste caso, Orah, Ilan e Avram, que nasceram em 1951 (em 1967 tinham 16 anos), têm 45 anos, e não 50 como o texto dá a entender em outros lugares. A determinação seria útil para 
localizar o contexto político, pois a segunda Intifada começou em setembro de 2000; se os amigos estão perto dos 50 anos, estaríamos no final de 2000 ou em 2001, em plena segunda Intifada.

Há também referência no texto ao ano de 2002 (p. 478). Mas esta indefinição não é muito relevante. O importante é que o casamento de Orah e Ilan se dissolveu, e Ofer acabou de concluir seu serviço militar de três anos. Para comemorar sua dispensa do exército, ele e Orah planejaram uma excursão pela Galileia. Porém, um dia depois de seu desligamento, Ofer volta para o exército para participar de uma ação de repressão contra palestinos. No táxi, levando Ofer para o ponto de encontro do exército, Orah percebe a situação como análoga a um festival de colheita em honra de divindades pagãs, que culminará em sacrifícios humanos:

Ela se vira para trás e observa a serpente de veículos, e a visão quase festiva, excitante, uma procissão gigantesca, multicolorida, cheia de vida própria: pais e irmãos e namoradas, e até mesmo avôs e avós, trazendo seus queridos para a base; o evento da temporada, ela pensa, em cada carro há um jovem rapaz, os primeiros frutos, um carnaval de primavera terminando com sacrifício humano, e você, ela pergunta a si mesma, olhe para si mesma, como você está trazendo seu filho lindo e arrumado, seu filho-quase-único, seu bem-amado, e Ismael como seu motorista particular. (p. 70)

Orah entra em pânico por causa da possibilidade de Ofer ser vitimado na ação, e concebe um estratagema, elabora um pensamento mágico: como o ritual do Estado estabelece que em casos de baixas de soldados uma comissão do exército deve visitar a família da vítima para dar-lhe a notícia, Orah decide manter o passeio pela Galileia, mesmo sem a companhia de Ofer. Assim, não podendo ser encontrada pela comissão da má notícia, estará a salvo, garantirá que nada acontecerá a Ofer; não haverá má notícia pelo simples fato de que a comissão não terá a quem transmiti-la. Este é o primeiro significado do título 
do romance: Orah foge das notícias, para evitar que haja notícias de seu filho. Esta interpretação óbvia é reforçada pela tragédia pessoal do autor, cujo filho Uri sucumbiu em agosto de 2006, nas últimas horas da segunda guerra do Líbano. Quando o livro foi publicado, Grossman declarou que "na época eu tinha a sensação - ou melhor, o desejo - de que o livro que eu escrevia o protegeria." ( $4^{a}$ capa da edição brasileira). Já imersa no âmbito do paganismo, como mostra a citação da página 70 , reproduzida acima, Orah elabora um complexo sistema de evitação, tentando construir um círculo mágico de proteção em torno de Ofer: não usar a palavra "morte" nem em pensamento, nem ao menos em sentido metafórico; não referir-se à impossibilidade de reencontrar Ofer sem estabelecer uma marca temporal ("não antes de..."), e assim por diante.

De volta para casa depois de deixar Ofer no ponto de encontro do exército, Orah recebe um telefonema de Avram. Num intrincado processo de rejeição e tentativa de aceitação, cumprindo uma espécie de promessa, outro pensamento mágico, Avram renunciara a comer carne e passara três anos marcando, com traços na parede junto a sua cama, cada dia do serviço militar de Ofer. Tendo chegado ao último dia, consegue reunir forças para telefonar para Orah, para confirmar que Ofer retornou em segurança. Ao saber que Ofer voltou para o exército, cai em profunda depressão, o que motiva Orah, a caminho da Galileia (de novo no táxi do palestino Sammy!), a parar em sua casa, para apoiá-lo nesta crise. Encontra Avram em tão mau estado, que decide levá-lo junto, contra a sua vontade, ou sem que sequer Avram entenda o que está acontecendo.

Assim, Orah e Avram estão na trilha.

Durante a caminhada, que durará o tempo da reincorporação de Ofer, os protagonistas terão ocasião de reavaliar suas vidas, seus relacionamentos, por meio de um trabalho de recuperação das memórias, e poderão sair da trilha transformados. $\mathrm{O}$ instrumento desta transformação é exclusivamente a palavra. Orah tentará fazer com que Avram lhe deixe falar sobre Ofer. Aqui convém notar o significado de seus nomes. Orah é "luz"; Avram, "pai exaltado", antes de se tornar Avraham, "pai de uma multidão de nações". O isolamento de Avram acaba por se romper e o casal consegue até mesmo voltar a ter relações sexuais. No final da trilha, Orah liga para sua casa de um telefone público e escuta várias mensagens deixadas por Ofer assegurando que está bem; a última mensagem é da noite anterior, e tudo acaba bem. 
Tudo acaba bem? Isto ainda deve ser visto.

O sofrimento de Orah com relação à possibilidade de Ofer ser vítima na ação é natural e perfeitamente compreensível. É sempre um fardo insuportável a perda de vidas humanas em conflitos armados, especialmente para as famílias das vítimas, e nenhuma mãe se sentiria confortável levando seu filho para a guerra.

Porém, se a tarefa do crítico é analisar a obra literária a partir do espanto que o texto lhe causa, e não pela aplicação ao texto de teorias previamente postuladas, é preciso registrar que a caminhada de Orah e Avram não será um passeio aprazível, de contemplação e fruição da natureza: a paisagem e os estranhos encontros ao longo da trilha levam o leitor a suspeitar de algo ainda desconhecido. $\mathrm{O}$ ritmo da narrativa, tão lento que até poderia parecer uma falha na construção do romance, é o mecanismo formal adotado pelo autor para reforçar esta suspeita.

Mesmo antes do início da caminhada, é possível perceber que o romance nos oferece não uma trama única, formada por oposições binárias (nós e eles; o exército israelense de um lado, os terroristas palestinos de outro), mas uma combinação de tramas, entrelaçadas e sobrepostas. Assim, o estado de desagregação psicológica em que Avram se encontra não é resultado somente de ter sido torturado pelos egípcios, mas também de ter sido colocado sob suspeita de traição pelo próprio exército israelense.

Outro ponto que chama a atenção do leitor é o fato de que o táxi que leva Orah e Ofer ao ponto de encontro do exército é dirigido por um palestino, Sammy, que há muitos anos presta serviços à família. O constrangimento a que o motorista é submetido (transporta um soldado que vai juntar-se a um exército prestes a iniciar uma ação de repressão contra o seu povo, sem ao menos ter sido informado disso previamente) não é imediatamente percebido por Orah, mas evidencia que israelenses e palestinos vivem histórias compartilhadas, ainda que suas respectivas narrativas os oponham.

Durante o percurso, o casal se depara com estranhos encontros: um grupo de inválidos levados a passear por um líder religioso carismático; um homem cuja esposa morreu há pouco, e que prometeu a ela que iria mesmo assim à excursão que tinham planejado; um bando de cachorros abandonados, que regrediram a um estado selvagem.

Também o ambiente físico é perturbador: incontáveis monumentos a solda- 
dos mortos em ação ou vítimas de ataques terroristas marcam a trilha por onde Orah e Avram caminham, lembrando um grande cemitério:

[...] até que Orah avista uma placa em memória do sargento Roy Dror, de abençoada memória, que foi morto sob este penhasco no dia 18 de junho de 2002, durante treinamentos da unidade "Duvdevan". "Ele caiu em silêncio como cai uma árvore, e o som de sua queda não se ouviu devido à areia macia" (O Pequeno Príncipe). Sem uma palavra, eles se levantam e se afastam dali para uma outra extremidade do pico, e no novo local também há um monumento, em memória do primeiro-sargento Zohar Mintz, morto no ano de 1996, em batalha no sul do Líbano, e Orah fica parada e lê com olhar dilacerado, Amava o país e morreu por ele, amavanos e nós o amávamos, e Avram a puxa pela mão, e ela não se move, e ele, à força, puxa-a para longe dali. Você tinha começado a contar sobre o Adam, ele a lembra, $e$ ela, ui, Avram, o que será? Me diga, qual será o fim disto aqui? Já não há lugar para tantos mortos. (p. 478)

Tendo no horizonte esta realidade exterior inóspita, o leitor acompanha o esforço de Orah para formular os principais acontecimentos da vida de Ofer, dos quais quer dar conta a Avram:

[...] se houver algum momento adequado, ela contará um pouco sobre Ofer, com cuidado, talvez aqui ele não se oponha tanto a isso, somente algumas coisinhas, talvez as coisas mais fáceis, engraçadas, do Ofer. Para que ele ao menos saiba quem é Ofer, mesmo que em linhas gerais, apenas os títulos dos capítulos. Para que ele ao menos agora conheça essa pessoa que trouxera ao mundo. (p. 156) 
Passam-se páginas e páginas sem que nada aconteça, sem que surja qualquer informação relevante. Por meio de fluxo de consciência, de monólogos interiores e de diálogos quase monólogos, pois Avram pouco interage, Orah volta em pensamento a diversos episódios do passado; promove uma reavaliação de sua vida, um profundo confronto com o que tem reprimido. A lentidão com que os fatos se revelam é funcional, corresponde ao temor de Orah de enfrentar essa reavaliação, insegura em relação ao que poderia vir a ser revelado; pode-se mesmo pensar que, retardando a ação, é instrumento do esforço de Orah para evitar ver-se face a face consigo mesma.

As precauções de Orah não conseguem impedir de todo a irrupção das verdades evitadas, e uma nova trama vai sendo construída com leves pinceladas, distantes umas das outras, como numa pintura impressionista. É preciso olhar com distanciamento para perceber corretamente o conjunto da obra, para entender que deve ser lida em mais de um plano. Numa metáfora musical, ouvem-se notas dissonantes, que apontam para o horror inominável. A primeira destas notas é que Ofer percebe as ações contra os palestinos como se se tratasse de um game de computador:

Ofer parecia querer, no último minuto, completar o que ficara faltando, e contou rapidamente sobre a pillbox onde tinha morado durante quatro meses na frente do bairro norte de Jenin, e como costumava ir todo dia, às cinco da manhã, abrir o portão da cerca em torno da pillbox, para verificar se os palestinos não haviam armado alguma cilada no portão durante a noite. E ela perguntou, e você ia lá, assim, sozinho? E ele disse: geralmente alguém da pillbox me protegia, quer dizer, se houvesse alguém acordado. [...] Ele foi se entusiasmando ao falar, como se contasse sobre um novo game de computador, e ela lutou o tempo todo contra a compulsão de pegar a cabeça dele entre as mãos e olhar dentro dos olhos dele para ver sua alma, que havia anos já vinha se apagando de sua mente. (p. 58) 
Na sequência (15 páginas depois!), o quadro da personalidade de Ofer que Orah, aos poucos, vislumbra, se agrava: ficamos sabendo que voltou para o exército não por ter sido reconvocado, como primeiro dissera para sua mãe: ele mesmo, ao saber da ação iminente, tomou a iniciativa de telefonar para sua unidade, apresentando-se como voluntário. Está ansioso por ir "para lá”; está ansioso por combater.

Será necessário que passem mais de duzentas páginas, que se atinja o meio do livro, para surgir uma primeira referência a certo ato perturbador cometido por Ofer durante o serviço militar, para que o leitor comece a sentir a "pancada na cabeça" de que falava Kafka. Enquanto Avram dorme, Orah registra em um caderno a seguinte reflexão:

E, apesar de tudo, posso dizer de coração aberto que desde o nascimento do Ofer até o episódio dele no exército, em Hebron, dois anos atrás, foi muito bom para todos nós juntos. (p. 293)

Passarão outras duzentas páginas para que Orah, ainda tentando minimizar a gravidade do episódio, contornando-o, tateando, negando, avançando e recuando, consiga formulá-lo um pouco menos vagamente, e comece a perceber sua importância para ela mesma:

Houve um problema, ela fala em voz baixa, não com ele, foi justamente com o Ofer, no exército, foi uma complicação só, uma besteira das grandes que a unidade dele fez em Hebron, ninguém morreu por causa disso, e o Ofer também não teve culpa, e muito menos a culpa foi só dele, havia vinte soldados ali, e por que justo ele? Não importa, agora não, eu cometi um erro, sei disso, e o Adam ficou muito bravo comigo por eu não ter apoiado o Ofer - ela respira fundo e vai liberando, uma a uma, num ritmo constante, as palavras que amarguram a sua vida desde então -, por não ter sido capaz de apoiar 
Ofer de todo o coração. Você entende? Você entende o absurdo? Pois com o Ofer eu já fiz as pazes há tempo, tudo está absolutamente em ordem entre nós - mas seus olhos vacilam um pouco, de um lado a outro -, e só o Adam, por causa daquela merda de princípios dele, não me perdoa até hoje. (p. 487)

Essas palavras, que Orah dirige a Avram, na verdade se dirigem a ela mesma.

Afinal, o que aconteceu? Durante uma ação, a unidade de Ofer prendeu um velho palestino, nu, dentro de uma câmara frigorífica. Quando se retiraram, ao final da operação, esqueceram de libertar o velho, que ficou lá durante dois dias. Só não morreu porque, por problemas de cortes no fornecimento de energia, o funcionamento da câmara era intermitente. Por causa do episódio, a corregedoria do exército abriu inquérito, e submeteu Ofer a interrogatório. Ilan e Adam apoiaram Ofer, asseguraram-lhe que não tinha porque se sentir culpado, mas Orah não. Escandalizou-se:

Embora Ofer já lhe tivesse implorado mais de uma vez que parasse de falar sobre isso, pelo menos em público, Orah sentiu-se obrigada a perguntar também a Dvir: mas como vocês não lembraram que ele estava lá? $\mathbf{E}$ Dvir encolheu seus ombros largos, não sei, talvez cada um tenha achado que o outro já o tinha tirado, e Ofer coçou o nariz, irritado, e Orah jurou a si mesma deixar de falar no assunto, não conversar sobre isso com eles nem que o mundo caísse, e os levou de carro, testa franzida e ombros contraídos quase até as orelhas. Mas como vocês puderam esquecer um ser humano!, as palavras escaparam-lhe da boca após alguns instantes, só me explique como é possível esquecer um ser humano num frigorífico durante dois dias. (p. 614) 
Orah não é capaz de superar o conflito entre a indiferença, a apatia que permitiria a manutenção dos vínculos familiares, e o que ela vivencia como imperativo ético:

\begin{abstract}
Pois eu, por exemplo, ela pensa, se daquela vez eu simplesmente tivesse calado a minha grande boca, talvez hoje eu ainda tivesse família. Afinal, eles, os três, Ilan e Adam e Ofer, pareciam estar constantemente avisando, sinalizando para ela de mil maneiras que há situações e questões nas quais é permitido se calar, simplesmente fechar a matraca, e não se é obrigado a botar para fora, em transmissão ininterrupta, todo o fluxo de consciência, não é? (p. 585)
\end{abstract}

A recusa de Orah a obedecer às leis do processo, segundo as quais os israelenses devem apoiar incondicionalmente quaisquer ações de seu exército, provoca o desmoronamento de sua família, microcosmo da sociedade.

As posições de David Grossman em relação ao conflito que opõe Israel aos palestinos são bem conhecidas. Juntamente com Amós Oz e A. B. Yehoshua, é um dos mais destacados proponentes da paz, da criação e reconhecimento de um Estado palestino ao lado de Israel. O autor vem elaborando essas posições em ensaios e entrevistas, que acabam reunidos em livros, infelizmente não traduzidos no Brasil. Em 1987, publicou Hazman hatsahov, traduzido em inglês como Yellow Wind; em 1992, Norrahim nifkadim (Sleeping on a Wire - Conversations with Palestinians in Israel); em 2003, Mavet kedererr haim (Death as a Way of Life: Dispatches From Jerusalem).

A mulher foge é, sem dúvida, um romance político, fortemente engajado na causa da paz. A literatura de ficção, pelo processo de particularização que lhe é próprio, permite refletir sobre uma sociedade a partir das ações, pensamentos, emoções de indivíduos. Analisando as relações de Orah com Avram, Ilan, Adam, Ofer e Sammy, Grossman desenvolve a tese de que a paz é necessária não só para evitar mais famílias israelenses enlutadas, mas também por causa dos conflitos éticos, para que a população israelense (e os judeus da diáspora) 
não se veja forçada a apoiar incondicionalmente um exército cujos membros podem sair de controle e banalizar a violência exercida sobre os inimigos, negando-lhes a condição de seres humanos; para que Israel, enfim, não precise assumir o papel de agressor, de potência ocupante; afastar-se da "miséria espiritual" de que falava Dante Alighieri.

A mulher foge é romance psicológico, onde a ação é irrelevante, e o que importa é o mergulho na mente das personagens. A obra é construída por contrapontos, em uma estrutura polifônica que permite abordar a complexidade das relações entre israelenses e palestinos: o motorista do táxi que leva um soldado israelense ao encontro do exército pode ser um palestino; uma das tarefas de que são incumbidos os soldados israelenses é a de policiar os acampamentos nos quais palestinos são confinados, sempre suspeitos de serem terroristas; israelenses são vítimas de ataques palestinos, mas também oprimem a população palestina em Israel e nos territórios ocupados. Trazendo para a trama como personagem, Sammy, o motorista palestino, permitindo-lhe externar sua contrariedade quanto à forma como é tratado pela israelense Orah, Grossman dá voz ao outro, ao silenciado pela metanarrativa oficial.

Mas não é apenas a defesa de uma causa justa que faz a grandeza da obra literária. A mulher foge é uma obra importante por seus aspectos estéticos, por sua forma. Para pôr em evidência a dificuldade de se lidar com um relacionamento tão complexo, Grossman se vale exclusivamente de mecanismos formais apropriados: como vimos, o Prólogo se estrutura como uma cena teatral, na qual o leitor assiste à formação dos complexos vínculos que unem os protagonistas; depois, o autor emprega amplamente técnicas de fluxo de consciência e escolhe uma forma narrativa que privilegia a lentidão no desdobramento dos fatos, para dar ao leitor acesso à sempre vacilante trilha psicológica percorrida pela protagonista. Isto requer o apagamento do narrador, colocado em segundo plano para aproximar o leitor do tumultuado psiquismo da protagonista. O narrador de $A$ mulher foge não tem autonomia para cumprir sua tarefa de conduzir a narrativa; assim como Avram, apenas pode seguir o ritmo imposto pela protagonista, que se esforça por retardá-la em sua fuga da realidade israelense.

No entanto, o conflito entre israelenses e palestinos já vem de muito longe. Por que, então, é importante ler $A$ mulher foge em pleno século XXI? O fracasso de tantos "processos de paz" que pareciam tão promissores, a ascensão dos partidos políticos que se opõem à criação de um Estado palestino e favorecem 
a multiplicação dos assentamentos - que vem ganhando força nas últimas eleições - conferem um grau de urgência à tarefa de sacudir a inércia, o conformismo, a apatia; quebrar o mar de gelo que há dentro de nós.

Não será otimismo pueril afirmar que a criação de um Estado palestino é inevitável. O que permanece indefinido é: quantas mortes ainda terão que ser lamentadas, quanto esforço ainda será desperdiçado, desviado da melhoria das condições socioeconômicas das populações? Por ser datada, a leitura do romance, no futuro, permitirá entender as questões enfrentadas por israelenses e palestinos antes de as relações entre os dois povos se normalizarem.

Não por acaso, o caminho percorrido por Orah e Avram se chama "trilha de Israel”, que "atravessa o país inteiro", "desde o norte", "até Eilat" (p. 310).

\section{Referência}

GROSSMAN, David. A mulher foge. São Paulo: Cia. das Letras, 2009. 